\title{
Los Apologi ad voluptatem de Marsilio Ficino: una exploración ontológica del placer
}

\author{
Marsilio Ficino's Apologi ad voluptatem: \\ an ontological exploration of pleasure
}

MARIANO ALEJANDRO VILAR*

\begin{abstract}
Resumen: Se conoce como Apologi ad voluptatem a cuatro relatos breves compuestos por Marsilio Ficino mientras elaboraba su Comentario al Filebo. Estos apólogos narran el origen del placer y su lugar en la creación del Universo, así como también su interacción con los distintos agentes que pueblan el cosmos. En todos ellos la voluptas ocupa un lugar ambiguo en relación con la bonitas, lo que implica que ante cada placer es necesario realizar un esfuerzo intelectual para comprender si está relacionado con el bien (el ascenso del alma) o con el mal (las limitaciones de la vida terrenal). En este artículo se propone un análisis de cada uno de los apólogos y una comparación con algunos textos filosóficos de Ficino. Palabras clave: Marsilio Ficino, Apologi ad voluptatem, Placer, Renacimiento, Neoplatonismo, Quattrocento.
\end{abstract}

\begin{abstract}
Apologi ad voluptatem is the name Marsilio Ficino gave to four short stories written while he was composing his Commentary on the Philebus. They relate the origin of pleasure and its place in the creation of the Universe, focusing in its interaction with the different agents that populate the cosmos. In all of them voluptas occupies an ambivalent place in relation to bonitas, which implies that an intellectual effort must be made to understand if each pleasure is related to the good (the ascent of the soul) or the bad (the material limitations of the earthly life). In this article we propose an analysis of each apologue and a comparison with some of Ficino's philosophical texts.
\end{abstract}

Keywords: Marsilio Ficino, Apologues, Pleasure, Renaissance, Neo-Platonism, Quattrocento.

Recibido: 06/03/2016. Aceptado: 08/10/2016.

* Doctor en Literatura por la Universidad de Buenos Aires. Docente en la Universidad Nacional de la Matanza. Becario posdoctoral del CONICET. Es miembro de la Asociación Argentina de Humanidades Digitales y co-editor de la revista Luthor. Sus líneas de investigación actuales son los debates acerca del significado placer en el cruce de la recuperación de Epicuro y Lucrecio en el siglo XV. Publicó recientemente un artículo sobre esta temática titulado «Pleasure and Variety in Thomas More's Utopia» (Moreana vol. 53, junio 2016). Actualmente se encuentra trabajando en una traducción al español del De voluptate de Lorenzo Valla. 


\section{Los Apologi ad voluptatem en la obra ficiniana y en el contexto del Quattrocento $^{1}$}

Se conoce como Apologi ad voluptatem a cuatro relatos breves escritos por Marsilio Ficino que tienen como temática la ubicación del placer (voluptas) en el cosmos ${ }^{2}$. Aunque su datación precisa no ha sido establecida, sabemos que fueron redactados al mismo tiempo que su Comentario al Filebo, ya que así lo narra en la epístola dedicatoria a Martín Uranio que aparece en el décimo volumen de sus Epistolae ${ }^{3}$. Si aceptamos la hipótesis de Allen (2000, 36), esto los ubica en los últimos meses de 1469, poco después de finalizado su Comentario al Banquete.

El problema de la voluptas no era nuevo para Ficino. En 1457 escribe el Liber de voluptate, el primer texto de su autoría que ha llegado hasta nosotros. Por el tono elogioso con el que se refiere a Epicuro y por su exhibición de un conocimiento de primera mano de los testimonios del corpus redescubierto de su escuela (a través de Diógenes Laercio y Lucrecio) este texto ha sido interpretado como una demostración de la revalorización parcial del interés que provocó al joven Ficino esta doctrina filosófica ${ }^{4}$. Estudios más recientes han demostrado, sin embargo, que la simpatía hacia algunas tesis epicúreas en el Liber de voluptate no opaca en ninguna medida su objetivo principal: la conciliación de Aristóteles y Platón (bajo el predominio de este último filósofo), es decir, la vía neoplatónica tradicional (Boulègue, 2007, 239).

Pese a compartir la misma temática, existen claras diferencias entre el Liber de voluptate y los Apologi ad voluptatem. Mientras que el primero está escrito en la forma de un tratado, los segundos son «apólogos» o fábulas, un género que resultaba especialmente atractivo para los humanistas del Quattrocento (Marsh, 2003). El carácter mismo de la voluptas está encarado también desde perspectivas muy diferentes, y su relación con problemas ontológicos lo acerca más al tratamiento que recibe en algunas secciones del Comentario al Filebo. Tampoco es evidente, en estos apólogos, la influencia de Epicuro. Desde nuestra

1 Este trabajo forma parte del proyecto de investigación «Traducción al español de obras (siglos XI-XV) receptivas y contextuales de las categorías anselmianas 'libertad', 'justicia', 'mal'» (PICT Código 2015-0255), con sede en la Universidad Nacional de San Martín (Argentina), dirigido por Enrique Corti y financiado por el CONICET.

2 Algunos autores llaman «apólogos» a los diez capítulos sueltos que figuran en los manuscritos completos del Comentario al Filebo (Vat. Lat. 5953 y Laur. Plut 21,8). Aquí, siguiendo el criterio empleado por Allen en su edición de dicho comentario (Ficino, 2000), utilizaremos esta denominación sólo para los cuatro capítulos que tienen la forma de apólogos.

3 «Cum vero amor nihil desideret aliud quam voluptatem, merito decimus hic liber consecratus amor finem in voluptatem facit, voluptate, inquam, Urania, ed est, caelesti, quando quidem haec Uranio dedicatur. Leges igitur, alter ego, hic iam in calce decimi nonnullos de voluptate apologos, dedicatos tibi quidem hodie, iamdiu a nobis excogitatus, dum Philebum Platonicum tranctantem commentaremur», Op. Omnia p. 921, citado por Marcel $(2007,323)$.

4 Sobre el regreso del epicureísmo en el Renacimiento véase Brown (2010) y Greenblatt (2011). Marcel (2007, 233) considera que Ficino pasó por un período dominado por cierto pesimismo materialista alrededor de 1458, donde es posible encontrar frases elogiosas a Lucrecio (donde lo llama por ejemplo «Lucretius noster»). Allen $(1989,193)$ destaca el hecho de que el reconocimiento por parte de Ficino de que la cosmovisión platónica y la lucreciana eran directamente opuestas hizo que se alejara progresivamente de este filósofo en su madurez, y que se esforzara por distanciarse de él en su Theologia Platonica. No por esto, sin embargo, deja de citarlo como una autoridad en relación a la teoría de la percepción que aparece en su Comentario al Sofista. 
perspectiva, sin embargo, el interés de Ficino en tratar el problema del placer forma parte del mismo clima intelectual que hizo que algunos aspectos del pensamiento epicúreo fueran revalorizados por autores como Lorenzo Valla o Francesco Filelfo ${ }^{5}$.

\section{Los primeros dos apólogos: el malus daemon y la carnada del placer}

Los dos primeros Apologi ad voluptatem presentan fuertes similitudes tanto en su estructura formal como en su desarrollo conceptual. El título del primero de ellos es «Malus daemon per verisimile ad falsum, per voluptatem trahit ad malum; Deus vero per haec ad verum et bonum». El texto comienza con una introducción puramente filosófica, en la que el narrador nos asegura que Dios es la única fuente de veritas y bonitas, y que esta última aparece en sus creaciones vinculada a la voluptas, que funciona como una «carnada» (esca) que debe conducirnos hacia las cosas buenas. La veritas, en cambio, se percibe a través de la marca de la verosimilitud. Ante esta disposición, aparece la envidia del demonio (invidus daemon) - un ser de cuyo origen no sabemos nada-, que intenta reproducir la estrategia divina y crear su propia imagen de lo verdadero y su carnada del bien. El narrador nos dice que «la marca de lo verosímil y la carnada similar al bien eran similares a aquellos de la divinidad, pero aquella invitaba a lo falso, esta a lo malo» («notam verisimilem et boni similem escam ad divinæ illius expressit similitudinem; adhibuit que tum illam falso, tum hanc malo.», Apologus I, p. 457) ${ }^{6}$. Este relato minúsculo finaliza con una exégesis platónica: «Por esto Platón llama al placer 'carnada de los males'» en el Timeo» («Hinc Plato malorum escam in Timaeo nuncupat voluptatem», Apologus I, p. 457) ${ }^{7}$.

El segundo apólogo se titula «Apologus de bonis atque malis» y presenta también el enfrentamiento entre dos potencias. Aquí tenemos, en vez del «Deus» y del «malus daemon» del primer apólogo, al «bien» y al «mal» personificados. Según el relato, en un comienzo el Bien y el Mal existían sin conflicto, pero cuando el Bien decidió comenzar a crear cosas buenas y el mal descubrió su propia esterilidad, recurrió a «Fortuna», quien lo asistió en la creación de cosas malas. Entre las diferencias entre las cosas malas y buenas, se destaca el hecho de que las cosas buenas tienen la voluptas ubicada «detrás», mientras que en las

5 Don Cameron Allen (1944), uno de los pioneros en el estudio del epicureísmo en el Renacimiento, se pregunta si puede decirse que Epicuro fue revalorizado debido a los cambios en la mentalidad de la época, o si más bien esos cambios deben atribuirse en parte al redescubrimiento de su filosofía.

6 Las citas pertenecen a la edición crítica bilingüe de Allen citada en la bibliografía (Ficino, 2000), que incluye tanto el In Philebum como los Apologi ad voluptatem. La numeración de los apólogos del I al IV fue añadida para facilitar su identificación, ya que Allen no incluye numeración alguna fuera del número de página. Las traducciones nos pertenecen en la totalidad de los casos.

7 Se refiere a Timeo 69d, donde Platón dice «Cuando éstos [los mortales] recibieron un principio inmortal de alma, le tornearon un cuerpo moral alrededor, a imitación de lo que él [el dios] había hecho. Como vehículo le dieron el tronco y las extremidades en los que anidaron otra especie de alma, la mortal, que tiene en sí procesos terribles y necesarios: en primer lugar el placer, la incitación mayor al mal, después, los dolores, fugas de las buenas acciones, además, la osadía y el temor, dos consejeros insensatos, el apetito, difícil de consolar, y la esperanza, buena seductora». Citamos según la traducción de Francisco Lisi. 
cosas malas el placer está por delante ${ }^{8}$. No contento con oponer sus propias creaciones a las del Bien, el Mal además utiliza al dios Momo para condenar a las cosas buenas por haber «ocultado su carnada» (escam occuluisset). La estrategia del Bien para asegurarse de que el Mal no pudiera triunfar consistió en imponer limitaciones a su poder. La primera de ellas es que las cosas malas serán atacadas por dos frentes: por otra cosa mala, y por una cosa buena. Ficino no da ejemplos pero es posible suponer que el esquema aristotélico del justo medio es lo que está detrás de este razonamiento9. La segunda es que aunque las cosas malas tuvieran el placer colocado por delante, este placer es breve comparado con el dolor al que inevitablemente conduce. Esto es lo que según Ficino quiso decir Pitágoras al afirmar que debemos apartarnos del «animal con la cola negra» («ab animali caudam habente nigram abstine», Apologus I, p. 467) ${ }^{10}$.

Llama la atención, en ambos apólogos, la confrontación maniquea de dos principios irreconciliables. Para Ficino, al igual que para Platón, los neoplatónicos y los teólogos cristianos influidos por estas corrientes, el mal no es otra cosa que la ausencia del bien, y por lo tanto no tiene una existencia en sí mismo (Kristeller, 1953, 57). En estos apólogos, sin embargo, no se explicita ninguna forma de vinculación entre Deus y el malus daemon o el Bien y el Mal, por lo que no sabemos si los segundos son alguna forma de emanación o creación de los primeros. Los atributos de Dios y del Bien son similares: infinita virtud, fuente de bondad y verdad. Del daemon y del Mal sabemos que son invidi (odiosos, envidiosos), y que no tienen la misma potencia generadora que su rival. Sin embargo, son capaces de crear por su cuenta o con ayuda de «Fortuna». Su conformación parece relacionada, por un lado, con la de Satanás, y por otro, con la de los demiurgos de más baja categoría en el Timeo platónico. Recordemos que son estos demiurgos los encargados de crear la carnada del placer en el alma humana. Satanás, el malus daemon por excelencia de la cosmogonía cristiana, también puede vincularse con el carácter envidioso del Mal, y con su capacidad para la tentación a través de engaños.

Mientras que estos apólogos relatan enfrentamientos, el modo exegético de Ficino se caracteriza, al contrario, por la conciliación ${ }^{11}$. En el Comentario al Filebo, los principios aparentemente opuestos de voluptas y sapientia se revelan como una falsa dicotomía que desconoce que la auténtica naturaleza del placer coincide con el acto intelectual más perfecto $^{12}$. El mal o «lo malo» son términos empleados en el Comentario sólo para caracterizar aquello de lo que huimos, ya que si entendemos correctamente la naturaleza de lo bueno,

8 «Videns enim bona referre bonum ad ipsumque conferre, habere virtutem, servare id in quo sunt, salute sua concordare inter se, habere a tergo voluptatem, contra haec obiecit opposita, scilicet degenerationem, impedimentum, numerosam turbam, impatientiam eius scilicet quod sustinet bonum, ítem ineptitudinem ad varia simul bona; deniqe voluptatem posuit in fronte mali». (Apologus II, p. 455)

9 Esto resulta claro cuando Ficino se refiere a que una cosa se opone tanto a su exceso como su carencia: «Sive enim per defectum fiat sive per excessum destruit tandem fundamentum quo sustinetur, a quo seorsum stare nequit.» (Apologus II, p. 465)

10 Esta sentencia figura en las «máximas» Pitagóricas referida en primer lugar a evitar el consumo de melanurus, un tipo de pez con la cola negra.

11 Hankins $(1990,355)$ analiza en detalle las estrategias conciliatorias empleadas por Ficino en sus comentarios, y destaca en particular su tendencia a desactivar aquellos aspectos de los textos paganos que parecen inducir a conductas contrarias a la moral de sus contemporáneos.

12 Ver In Philebum I, XXXII. 
esta nos conduce inevitablemente hacia sí misma. Ficino emplea aquí numerosos argumentos tomados de la Summa contra gentiles de Tomás de Aquino para apoyar una tesis intelectualista del summum bonum, según la cual la voluntad está subordinada al intelecto. En estos primeros apólogos no hay una reflexión explícita acerca de cómo el ser humano puede distinguir el anzuelo del bien (la voluptas que es señal de la bonitas) del anzuelo del mal, pero es posible suponer que esto depende en gran medida de la capacidad intelectual de identificar la colocación del placer en relación con los bienes.

Este problema nos conduce de forma directa a la cuestión de la voluptas en el esquema ontológico creado por Ficino en estos apólogos. La cuestión más ambigua es sin duda el problema de las «marcas», asociadas en primer lugar con las dos carnadas y con la actividad demónica $^{13}$. En su Theologia Platonica Ficino relaciona esta teoría con el Génesis, donde la serpiente presenta al fruto prohibido como placentero (Gén 3: 6) ${ }^{14}$. Los daemones más peligrosos son aquellos que nos arrastran hacia el mundo material y nos alejan del espiritual, pero su influencia puede ser combatida mediante las oraciones. En el Comentario al Sofista, donde continúa reflexionando sobre estos seres, la oposición misma entre el filósofo y el sofista replica la que se produce entre el placer que funciona como carnada del bien y el placer que conduce al mal. El primero es un verus imitator y el segundo es un fallax aemulator que no busca producir una imagen de las cosas verdaderas en sí sino que utiliza engañosamente estrategias que imitan la actividad filosófica ${ }^{15}$. En otras secciones, Ficino se refiere al sofista como un imitator ironicus que tiene la intención determinada de producir engaños y oculta su verdadero rostro. A su vez, al reflexionar sobre la magia, Ficino establece también un paralelismo entre los daemones, la imaginación y la actividad sofística, ya que todas ellas son fuerzas capaces de crear ilusiones que no están inspiradas en la verdad, y de producir por lo tanto una combinación entre ser y no ser. Nuestra imaginación es en sí misma una suerte de fuerza demónica en la medida en que es capaz de fantasear y de apartarse de la verdad ${ }^{16}$.

Para imitar al filósofo y tergiversar sus nobles intenciones, el sofista (al igual que los daemones inferiores), imita la Naturaleza, que no es otra cosa que el principal instrumento divino ${ }^{17}$. En otras palabras, mientras que Dios crea imitando las Formas y plasmándolas en la Naturaleza, los daemones crean imitando la Naturaleza para sus propios fines. Esto es lo que sucede con la voluptas en los primeros apólogos, que es imitada en tanto marca o señal de bonitas. Al hacerlo, se produce un quiebre entre la relación bonitas-voluptas, lo que implica a su vez un quiebre en la relación entre el ser (ens) y sus representaciones. La voluptas se autonomiza de las creaciones divinas y su significado queda en una zona indefinida respecto de lo bueno y de lo malo. Los afectos humanos no son una guía infalible hacia la verdad.

13 Es muy posible que Ficino se haya inspirado aquí en el Fedro (240a-b).

14 «Certe Plato in libro De pulchro, quasi sicut Moyses, inquit daemonem quendam ab initio voluptatem plurimis malis immiscuisse» (Theologia Platonica XVI, II, 14). Citamos según la edición de Hankins (Ficino, 2001) listada en la bibliografía final.

15 Esto aparece sobre todo en el Argumentum que da inicio al comentario. Véase las pp. 218-219 en la edición de Allen (1989) citada en la bibliografía final.

16 Allen $(1989,181)$ señala que en este y otros pasajes no es claro si Ficino piensa en la influencia demónica como algo que sucede por fuera de la conciencia y se le impone, o si es un producto mismo de la actividad de la imaginación humana.

17 Ver cap. 46 del Comentario al Sofista (pp. 270-277) 
Es casi inevitable pensar que Ficino podría haber simplificado ambos relatos omitiendo la idea de la voluptas como carnada. Si Dios se hubiera limitado a difundir su propia bonitas y el malus daemon a producir la voluptas como una copia inferior y peligrosa, estos apólogos no se prestarían a mayores ambigüedades ${ }^{18}$. Sin embargo, el filósofo florentino optó por resaltar el carácter ambivalente del placer e incluso por poner en escena en primer lugar su conexión con el Bien supremo. Desde nuestra perspectiva, esto se debe en primer lugar a su deseo de reconsiderar positivamente el alcance de la voluptas en contra de las tradiciones ascéticas (filosóficas y/o monásticas) que pretendían refutarla por completo. La posición de Platón, incluso con sus ambigüedades y oscilaciones en los diferentes diálogos, es más cautelosa al respecto ${ }^{19}$.

La consecuencia de esta operación narrativa y conceptual es que por un lado la bonitas parece volverse dependiente del agregado de la voluptas (así como la veritas de la marca de la verosimilitud), y por otro, no queda resuelto con claridad en qué medida la voluptas que es «carnada del mal» puede ser una imitación del placer sin tener una relación con la bonitas a su vez. No parece tratarse aquí de una degradación ontológica como sucede con la copia de la copia en la teoría de la mímesis platónica. Predomina, en cambio, la idea de que el carácter de «suplemento» propio de la voluptas es lo que permite que el malus daemon pueda establecer una cesura entre placer y bien y usarla a su favor. Esto no podría suceder con la bonitas en sí, que es un atributo divino esencial.

Poco nos dicen estos dos apólogos sobre la manera en que los seres humanos pueden identificar de forma precisa qué placeres han de seguir y cuáles han de evitar. La distinción más clara que se nos ofrece es la que nos señala que los placeres del bien son colocados «por detrás» de las cosas (a tergo) y los del mal «adelante» (in fronte). Podemos interpretar que esta distinción espacial se refiere metafóricamente a una cuestión temporal: las cosas malas causan placeres inmediatos, mientras que las buenas no se nos ofrecen en primera instancia a través de la carnada del placer, sino que este aparece a posteriori. Aunque es posible deducir una ética aquí que tiene rastros de epicureísmo (en la medida en que reconoce que es fundamental calcular la elección de los placeres tomando en cuenta los efectos a largo plazo antes que su efecto inmediato), el escaso desarrollo que posee la cuestión es revelador de una de las características principales del tratamiento ficiniano de la voluptas. Para este autor, el lugar del placer es en primera instancia un problema ontológico. Sus consecuencias éticas no se miden en base a los actos que deben realizar los hombres y mujeres en su vida diaria, sino en relación con la posibilidad de orientarse en relación con las fuerzas creadoras del cosmos y el efecto distorsionador de los daemones.

18 Dado el carácter profano y frecuentemente condenado del término voluptas en la tradición clásica (véase sobre todo en Séneca la epístola LIX a Lucilio, y en Cicerón, la refutación del epicureísmo en el libro II del De finibus), no hubiera resultado sorprendente que Ficino hubiera tomado esta palabra para la versión degradada de la bonitas producida por el malus daemon.

19 La valoración platónica del placer es un tema de gran complejidad que no intentaremos abordar aquí. Véase al respecto Bossi (2008) y Lefevbre (2011). 


\section{Palas Atenea y Voluptas: el tercer y el cuarto apólogo}

Los enfrentamientos que aparecen en los dos últimos apólogos involucran un número mayor de personajes. El tercero se titula «De voluptate quae vincit ambitiosos, victa est a Pallade» y tiene como protagonistas centrales a los Placeres (Voluptates) y a Palas Atenea. El relato comienza con el descubrimiento por parte de los Placeres (que aparecen siempre como un colectivo en este apólogo) de que existen hombres ambiciosos que hablan en su contra. Frente a esta situación convocan en su ayuda a Impudentia, quien los incita a aparecer frente a los hombres ambiciosos para demostrarles a todos que aquellos que pretenden despreciarlos los anhelan sólo para ellos mismos. Luego de esta primera victoria, los Placeres descubren la existencia de enemigos más peligrosos: los filósofos, que declaran seguir sólo a Palas. Aquí la confrontación se transforma en un juicio: Júpiter será el juez, y los Placeres convocan como abogada a Temeritas mientras que Palas se defiende a sí misma. El proceso consiste en primer lugar en una disputa verbal en la que tanto Temeritas como Palas proclaman la primacía lógica y temporal de los principios que cada una defiende: voluptas y sapientia. La pregunta que recorre la argumentación es si los filósofos buscan el conocimiento por el placer que les produce, o si en cambio el placer es un mero subproducto del conocimiento. Esta cuestión queda abierta ya que Temeritas decide cambiar de estrategia y presentar una apología de la voluptas inspirada en la invocación a Venus con la que comienza el De rerum natura:

Mira alrededor tuyo Júpiter y observa qué amplio que es el dominio del placer. He ahí Venus, he ahí Cupido, sus adherentes. De él son seguidoras las Gracias, y el mismo dios de los jardines es su ministro. De él también es Ceres en la taberna y Baco en la despensa. De él es la ambrosía y el néctar que todos los dioses disfrutan. ¿Por qué debo recordarte a Marte y a los dioses ferocísimos? ¿Por qué debo recordarte a ti mismo Júpiter? ¿Por qué debo recordarte a otros que en todas partes son atrapados por los encantos del amor? Y todo el resto, finalmente, con la violencia apenas pueden alcanzar y apenas pueden retener a cualquiera, pero un gesto cualquiera [del Placer] los llena de felicidad, y este a nadie obliga, conduciendo a todos por voluntad propia, retenidos porque lo desean. Y el placer guía no solo a los que viven en la tierra, sino también a los que viven en el cielo y a los que comandan en el cielo. Y no solo a los vivientes sino también a los no vivientes lleva hacia sí el placer de cualquier tipo ${ }^{20}$.

Palas no busca contrarrestar esto con palabras, sino que opta por una demostración práctica. Convoca a la corte a Pavor. Cuando los Placeres oyen que se anuncia su llegada, huyen despavoridos junto con Temeritas. Luego de que los dioses presentes terminen de reírse de

20 «Circumspice Jupiter quam amplum sit voluptatis imperium. En Venus, en Cupido huius astipulatores. Huius et pedissequæ gratiæ, huius et hortorum deus ipse minister. Huius in popina Ceres, atque Bacchus in penu. Huius ambrosia nectareque coelestes cuncti vescuntur. Quid memorem Martem deorum ferocissimum? Quid te ipsum Jupiter? Quid ceteros venereis passim illecebris irretitos? Et quidem ceteri violentia tandem vix assequuntur vixque retinent, una hæc uno quodam nutu feliciter implet, nullum trahens, omnes volentes ducens, retinensque libentes. Neque solum quæ in terra vivunt sed quæ in cœlo et quæcœlum ducunt ipsa ducit. Neque viventia solum sed etiam non viventia rapit ad se quæque voluptas». (Apologus III, p. 470) 
lo sucedido, Palas explica que nada hay más vil que la voluptas, ya que esta no es capaz de enfrentar siquiera la mención del nombre del miedo. La conclusión de la fábula, puesta en la boca de la misma Palas, es que ante el peligro el placer no sólo desaparece, sino que incluso se convierte en su opuesto, el dolor.

El cuarto y último apólogo mantiene muchos de los mismos protagonistas, pero el rol que cumplen es diferente. Su título es «De voluptate, quod non sit cum ipsa congrediendum neque in terris speranda». En este caso el conflicto inicial es la preocupación de Júpiter frente al hecho de que los mortales prefieren permanecer en el mundo terrenal, donde conviven con los placeres, que dirigirse al cielo. Por este motivo, decide intentar derrotar al placer y envía sucesivos emisarios. En primer lugar envía a Vulcano y Marte, que fracasan porque el placer logra seducirlos con sus encantos. Luego envía a Palas, pero a diferencia de lo que sucedió en el apólogo anterior, aquí la diosa fracasa puesto que el carácter escurridizo del placer supera sus armas y sus argumentos. Habiendo sido derrotados sus emisarios, Júpiter consulta a su padre, Saturno, representante de la vida contemplativa, quien le señala que Voluptas no puede desaparecer ya que es, junto al dolor, uno de los impulsos básicos que mueven los espíritus. Por este motivo, aconseja llevar a Voluptas al cielo, y dejar en la tierra al dolor. Esto se logra mediante la intervención, ahora pacífica, de Palas, quien aconseja que una comitiva comandada por Apolo, Mercurio, las Musas y las Gracias visite a Voluptas en la tierra y la conduzca hacia la morada celestial. Esto último sucede, según el narrador, en el momento en que Adán pecó y Astrea, la representación de la Justicia, dejó la Tierra ${ }^{21}$. Finalmente, Plutón aprovecha las vestimentas que Voluptas dejó al ascender al cielo para cubrir con ellas a la Furia Iactura («pérdida» o «perjuicio»), quien engaña a los mortales. La advertencia final es que por este motivo debemos evitar el placer: «De ahí que somos aconsejados a escapar lejos del placer, no sea que bajo el manto del placer caigamos de inmediato en el perjuicio» (Apologus IV, p. 479) ${ }^{22}$.

Aunque el argumento de estos apólogos está dominado por fuerzas cósmicas, los seres humanos tienen su rol más protagónico en el tercero, donde por única vez aparecen divididos en subgrupos: los ambiciosos y los filósofos ${ }^{23}$. Sin embargo, su función sigue siendo pasiva, ya que la acción está reservada a las figuras divinas, que se organizan de acuerdo a alianzas y enfrentamientos. El placer convoca asistentes en el tercer apólogo (Impudentia y Temeritas, respectivamente), mientras que en el cuarto, son los distintos emisarios o asesores de Júpiter quienes estructuran la evolución de la trama.

Cabe preguntarse por qué Palas sale victoriosa en el tercer apólogo y es derrotada en el último. En el tercer apólogo la batalla se da en términos legales y oratorios, mientras que en el cuarto la victoria de Voluptas proviene de su carácter escurridizo, contra el que las armas de Palas fallan una y otra vez. El enfrentamiento (o al menos la tensión) entre la sabiduría y el placer como guías para la vida estructura el debate entre Sócrates y Protarco en el Filebo,

21 «Sed quonam tempore voluptas aufugit in cœlum? Quo et Astræa originalis scilicet iustitia Adam peccante.» (Apologus IV, p. 477).

22 «Hinc admonendi sumus ut voluptatem procul effugiamus, alioquin sub voluptatis prætextu in latentem iacturam protinus corruemus». En su Comentario al Sofista Ficino relaciona los mali daemones con las furias.

23 No ahondaremos aquí en la cuestión, pero es interesante comparar la distribución de tipos de personajes con otros fabulistas del Renacimiento. Al respecto véase Marsh (2003, 20) quien destaca las figuras de Alberti y Scala, contemporáneos de Ficino. 
y es indudablemente uno de los temas mayores del comentario ficiniano a ese texto. El hecho de que en los apólogos no exista una resolución definitiva a esta batalla muestra que para Ficino no podía zanjarse la cuestión con una simple declaración de principios a favor de la sapientia y el intellectus. El ideal de la vida contemplativa y el ideal de la vida hedonista no pueden separarse del todo si nos mantenemos fieles al objetivo de presentar un summm bonum tan perfecto como atractivo para la totalidad de los seres humanos.

Es posible hipotetizar que el motivo tras los diferentes resultados de cada enfrentamiento está relacionado con la caracterización misma del placer en cada apólogo. Hemos visto que en el tercero no se habla de Voluptas sino de Voluptates, es decir, no se trata de una divinidad/personificación singular sino de un colectivo. Por este motivo también su huida del juicio frente a Júpiter resulta especialmente ridícula: se trata de una turba huyendo de forma caótica y desordenada. Es posible que aquí Ficino tuviera en cuenta un aspecto esencial de su caracterización del placer, que aparece mucho más desarrollado en su Comentario al Filebo que en el texto platónico original. Interviniendo directamente sobre una respuesta de Sócrates a Protarco (Filebo 14b), Ficino escribe en su comentario:

Así pues, dejadas de lado estas nimiedades, debemos establecer por este motivo que los placeres son muchos y disimiles tanto en mi discurso como en el tuyo. También son muchas las ciencias, pero no existen ciencias contrarias. Si alguna lo fuera, las ciencias de las cosas contrarias entre sí serían contrarias también, lo que es falso. Están en la misma alma al mismo tiempo. Al contrario, por lo general la misma disciplina trata sobre cosas opuestas. Por ende no escondamos las diferencias entre tú bien y el mío, Protarco, sino que coloquémosla en el medio, para que a partir de una correcta refutación se descubra si es o bien el placer o bien la sabiduría o bien alguna tercera cosa ${ }^{24}$. (In Philebum, I, XV, pp. 163-165)

En otras palabras, no podría existir una multitud de Palas Ateneas en el mismo sentido que existe una multitud de voluptates ${ }^{25}$. Incluso podemos suponer que si en el tercer apó-

24 «Nugis itaque huiusmodi prætermissis, par istud in tua ac mea oratione ponendum ratumque habendum ut multæ sint et dissimiles voluptates. Multae quoque differentesque scientiæ; contrariæ tamen scientiænullæ sunt. Siquæ enim tales essent, maxime contrariorum scientiæcontrariæ forent, quod quidem falsum est. In eodem enim animo sunt eodem in tempore. Immo oppositorum eadem ferme est disciplina. Ergo ne differentias tui meique boni abscondamus, Protarche, sed in medium adducamus, ut ex recta redargutione comperiatur utrum voluptas ipsum bonum sit vel sapientia vel tertium aliquid.»

25 Para observar la intervención de Ficino sobre este pasaje platónico basta compararlo con su propia traducción del Filebo. Allí esta intervención de Sócrates aparece con los siguientes términos:«Mihi igitur et in tua, et in mea oratione ex aequo id placet: ut multae videlicet voluptates ad dissimiles sint, multae praeterea differentesque scientiae. Differentiam itaque mei ac tui boni, O Protarche, minime abscondentes, sed in lucem potius educentes, feramus, si qui examinantes inquirant, voluptatemne an sapientiam, aut tertium praeter ista quiddam bonum vocare fas sit.» (Philebus, p. 58). Citamos la traducción de Ficino según la edición incluida en la bibliografía final (Platón, 1518). A simple vista se percibe como Ficino añade una aclaración acerca de la imposibilidad de que existan ciencias opuestas entre sí. El texto del Comentario al Filebo nos indica que su autor no podía concebir la idea de que hay saberes que se opongan, ya que el alma tiene el poder de unificarlos. Esta deducción deriva de la concepción ficiniana que ve en el alma la copula mundi que pone en relación armónica todos los planos, desde Dios hasta los seres más terrenales. Véase al respecto Kristeller (1953) y la Theologia Platonica. 
logo los placeres necesitan ser representados por otras figuras (Impudentia y Temeritas) es debido a que conforman un grupo indefinido, incapaz de agruparse bajo la estabilidad de un único genus.

Recordemos que no sólo las Voluptates son derrotadas, sino que además, de acuerdo al juicio de Palas, su naturaleza es tan volátil que es fácil que se conviertan en su propio opuesto, es decir, el dolor. Esto parece estar inspirado de nuevo en Platón, pero no en el Filebo sino en la siguiente observación de Sócrates en el Fedón:

¿Qué cosa más extraña, amigos, parece eso que los hombres llaman placer! ¡Cuán sorprendentemente está unido a lo que se semeja su contrario: el dolor! Los dos a la vez no quieren presentarse en el hombre, pero si se persigue el uno y se le coge, casi siempre queda uno obligado a coger también al otro, como si fueran dos seres ligados a una única cabeza. Y me parece -agregó- que si hubiera caído en cuenta de ello Esopo habría compuesto una fábula que diría que la divinidad, queriendo imponer paz a la guerra que se hacían, como no pudiera conseguirlo, les juntó en el mismo punto sus coronillas; y por esta razón en el aquel que se presenta el uno le sigue a continuación el otro. (Fedón, 60b-c) ${ }^{26}$

Aunque la reflexión de Palas («in hostem et id quidem súbito [transformatur]») va en línea con lo que aquí dice Sócrates, es llamativo que Ficino, quien se propuso precisamente elaborar fábulas sobre el placer, no utilice esta idea en ninguno de sus apologi. La relación placer-dolor, que intrigaba a Platón y que continúa suscitando reflexiones hoy en el campo del psicoanálisis, no parece haber interesado a Ficino de la misma forma que la relación entre placer y conocimiento.

Una obra pictórica de Andrea Mantegna que data de principios del siglo XVI, titulada Palas expulsando a los vicios, pudo haber sido inspirada por este apólogo. Vemos en ella a la diosa de la sabiduría plenamente armada con la misma lanza y escudo que, en el cuarto apólogo de Ficino, resultaban inútiles contra Voluptas. Marcha aquí hacia un conjunto de seres deformes que se encuentran en un pantano. Estos seres representan vicios tales como la pereza, la avaricia, la ignorancia y la concupiscencia. En el cielo encontramos las virtudes de la moderación, la justicia y la fortaleza. Si bien hay muchos elementos en el tercer apólogo que no corresponden con esta iconografía, la huida desordenada de los vicios en el cuadro de Mantegna puede estar parcialmente inspirada por el relato ficiniano, en donde la multitud de voluptates también se ve obligada a abandonar la confrontación frente a la diosa Palas.

El cuarto y último apólogo encuentra a Palas derrotada en la lucha con armas y palabras, pero aparece victoriosa cuando asume su misión como emisora de la oferta de paz de Júpiter. Aquí podemos leer una posible intención alegórica de Ficino, no del todo explícita: el intelecto es superior al placer sólo en la medida en que no destina sus esfuerzos a intentar suprimirlo. De otra forma, la ubicuidad del placer y su vínculo indisociable con la idea de la felicidad (es decir, de la bonitas divina) lo vuelven invulnerable. La alianza entre Palas (en esta ocasión llamada Minerva) y Voluptas es declarada explícitamente en el apólogo: «Pues

26 Citamos según la traducción de Gil Fernández (Platón, 2004). 


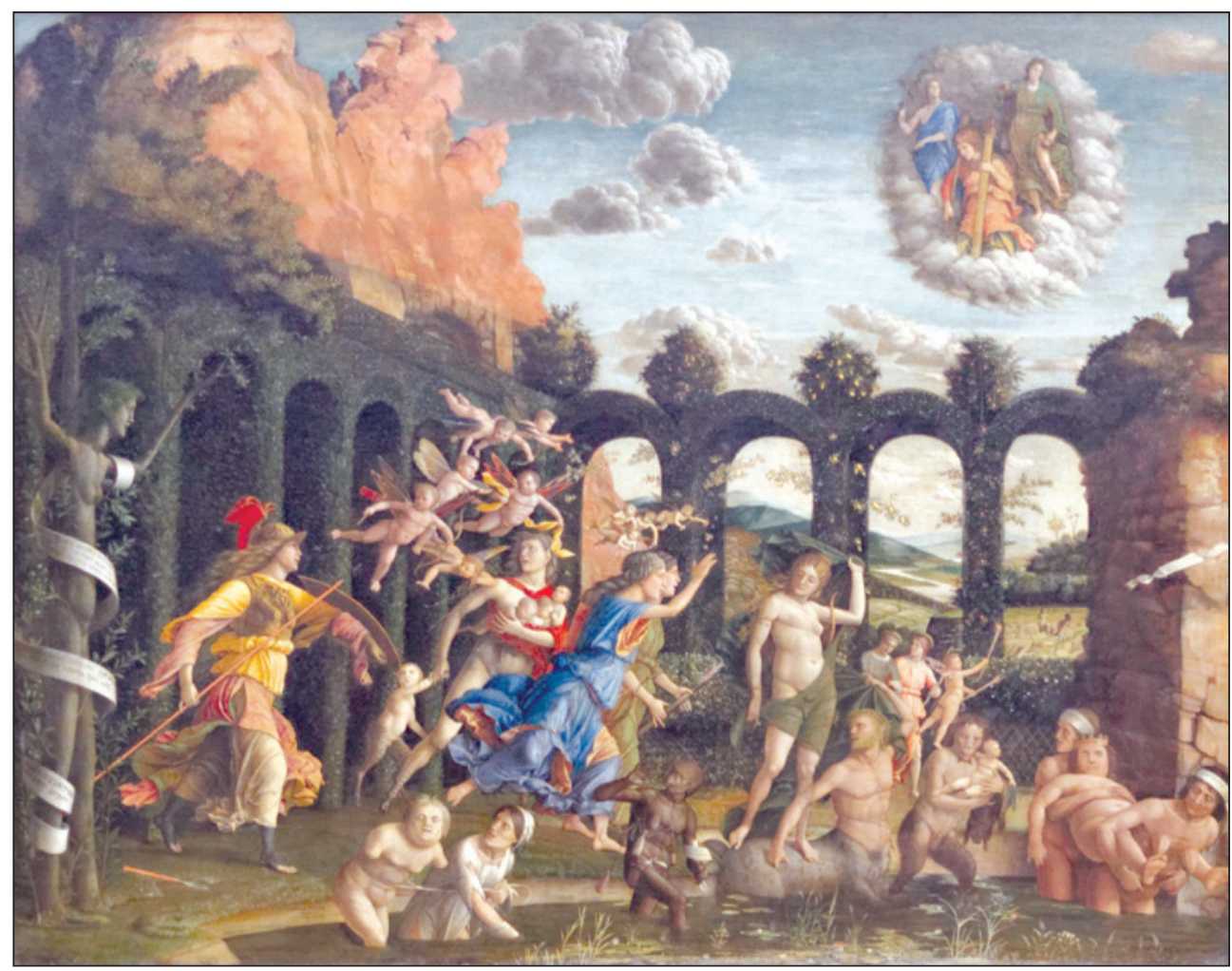

Andrea Mantegna, Palas expulsando a los vicios. Óleo sobre lienzo. Louvre.

Fuente: Web Gallery of Art (http://www.wga.hu/).

cuando [Voluptas] fue conducida por Mercurio, Febo, las Musas y las Gracias, fue transferida a Minerva. De forma que sólo podemos obtener el placer pleno de la sabiduría divina, y también hay cierto deleite a partir de las disciplinas liberales» (Apologus IV, p. 478)27.

El último apólogo diferencia con claridad el placer real de la imagen del placer (donde se esconde Iactura), mientras que en el tercero estos aparecían mezclados bajo el colectivo Voluptates. Debido a esto, el cuarto apólogo retoma la estructura que encontrábamos en los primeros, ya que Plutón funciona como el malus daemon y la Furia como su carnada. Sin embargo, aquí nos encontramos con una clara diferencia, y es que ahora lo que separa los placeres auténticos de los falsos es su ubicación en el cosmos. Los mortales no estarían, por lo tanto, frente a la disyuntiva de si deben o no evitar los placeres, ya que todos aquellos que conocen a través de sus sentidos pertenecen a Plutón. De ahí que el cuarto apólogo concluya con una tajante directiva de evitar los placeres sin aclarar de qué tipo se

27 «Nam ad Minervam [Voluptas] translata est, Mercurio, Phœbo, Musis, Gratiis perducentibus. Quamobrem voluptatem plenam penes divinam sapientiam tantum assequi possumus, delectationem etiam quamdam ex liberalibus disciplinis.» 
trata («Hinc admonendi sumus ut voluptatem procul effugiamus»). Entendida en términos literales, la conclusión impide considerar de forma positiva cualquier búsqueda de placer, lo que en cierta medida se contradice con el reconocimiento de que hay delectatio en las artes liberales. ¿Hasta qué punto la separación entre un placer real (originalmente ubicado en la tierra pero luego desplazado hacia el cielo) y otro que es sólo apariencia implica que no podamos tener ningún contacto terrenal con la vera voluptas?

Además de las artes liberales, Ficino se refiere a la esperanza (spes) entregada por Júpiter a los mortales para aliviar su vida al haberse retirado el placer de su dominio:

Pero para que los mortales, privados del placer, rodeados de adversidades, no se agredan entre sí y se destruyan, Júpiter, compadecido, cuando sustrajo el placer multiplicó para nosotros la esperanza (spes). Pero la esperanza conseguida aquí, esto es, la que se obtiene de las cosas mortales, engaña ${ }^{28}$.

La relación entre voluptas, spes y vida terrenal es fundamental para comprender el rol del ser humano en la tierra una vez que se ha aceptado que el placer auténtico es solamente celestial. Lorenzo Valla llegaba al misma conclusión en el libro tercero de su De vero bono cuando, luego de afirmar que la voluptas es duplex (una celestial y otra terrenal), declaraba que es posible obtener una cierta forma de placer en esta vida terrenal siempre y cuando esté orientado por la esperanza de uno celestial. Sólo el placer terrenal que no contempla esta esperanza como un elemento constituyente es en sí mismo mater vitiorum ${ }^{29}$. Lo mismo parece aquí decir Ficino al indicar que la spes remedia la ausencia de placeres reales en nuestra vida cotidiana. En otras palabras, funciona en gran medida como la «carnada del bien» de los primeros apólogos, ya que es ella la que nos conduce hacia la morada celestial. A esto se refería el segundo apólogo al hablar de la voluptas puesta «por detrás» en los bienes producidos por Dios. Esta postergación del placer es análoga a la esperanza que infunde Júpiter y que nos permite orientarnos hacia el cielo incluso en un mundo dominado por el dolor y las Furias. Sin embargo, tampoco la spes carece de peligros, ya que ella también tiene una contraparte terrenal.

\section{Conclusiones}

Más allá de las diferencias que encontramos en la estructura de los dos primeros apólogos en relación con los últimos, la persistencia de algunas temáticas es evidente. En los cuatro textos las fuerzas cósmicas operan bajo el presupuesto de que el rol del placer depende de su capacidad para atraer hacia sí a los seres animados. Con este propósito, los antagonistas del Bien/Dios/Júpiter «duplican» al placer generando una versión que resulta afín a sus propósitos. Esta nueva voluptas no se conecta con el Bien ni con ninguno de sus atributos, sino que en cambio responde a los fines de su creador. Mientras que en los dos primeros apólogos

28 «Sed ne mortales orbati voluptate inter tot adversa se afflictarent et perderent, Jupiter miseriæ nostræ misertus dum abstulit voluptatem spem nobis multiplicavit. Sed fallit spes voluptatis hic consequendæ, id est, ex rebus mortalibus reportandæ». (Apologus IV, p. 477)

29 Ver De vero bono, III, X, 1. Bokdam (2010) señala algunos aspectos en común entre este texto de Valla y los Apologi ad voluptatem, sin presentar sin embargo un análisis de cada uno como el que proponemos aquí. 
esto sucede de forma literal y transparente (de ahí que sean relatos puramente conceptuales), en los últimos esta dinámica aparece representada por la interacción de personajes mitológicos. No se habla allí de bonitas como un atributo que emana directamente de Dios, sino del ascenso al cielo. La carnada del placer se convierte en una esperanza (spes), la única imagen de la voluptas que no fue distorsionada por Plutón.

El tercer apólogo es el único en el que el placer aparece presentado como un colectivo que no se somete a una dualidad verdadero/falso o bueno/malo. Las Voluptates vencidas por la argucia de Palas no tienen un par opuesto que se les confronte. De ahí que resultara en cierta medida posible asimilarlas sin más a los vicios y vincularlas (según el dictum platónico-socrático) con el dolor en el que pueden transformarse. Por otro lado, aunque la caracterización de los placeres es en este apólogo sin duda inferior a la de Palas, su cruzada al comienzo del relato para demostrar la falsedad de los hombres hipócritas y ambiciosos demuestra que las voluptates pueden actuar como una fuerza positiva en el Universo, al menos en la medida en que reconozcamos los límites de su imperium.

La capacidad del placer para atraer hacia sí a los seres humanos, observable empíricamente y reconocida desde los inicios de la ética filosófica, no podía ser dejada de lado por Ficino en su búsqueda de explicitar los procedimientos por los que el alma asciende hacia la divinidad. De esta manera, aunque su concepción de la vida contemplativa implicaba darle un lugar privilegiado al intelecto, la voluptas tiene que ocupar un espacio relevante ${ }^{30}$. En estos textos no se trata, como en Epicuro, de una prudencia (phrónesis) cuyo objetivo principal consiste en discriminar placeres en base a su efecto en nuestra armonía y salud. El intelecto, para Ficino, siempre implica una proyección hacia los planos superiores, es decir, un impulso metafísico. El hecho de que la voluptas sea la marca elegida por Dios/el Bien/ Júpiter para atraer hacia la auténtica bonitas da a entender, desde nuestra perspectiva, que ningún placer debe rechazarse a priori, ya que en todos ellos es necesario elucidar si se trata de verdaderas imágenes del bien o de carnadas falsas.

No aparecen en ninguno de los apólogos condenas a placeres específicos que nos permitan descartarlos de la esfera del summum bonum. Vimos, sin embargo, que tanto el segundo como el cuarto apólogo enfatizaban la idea de que el placer que está asociado con el Bien y con el ascenso espiritual se caracteriza por aparecer en segunda instancia. Está a tergo de las cosas que lo suscitan, y se identifica con la esperanza. En este sentido, todo aquello que produzca satisfacción inmediata parece quedar descartado. ¿Significa esto que los placeres sensibles pierden toda relación con el sumo bien? No necesariamente, ya que experiencias sensoriales como los del sexo y la alimentación pueden ser buscados por sus efectos ligados a la supervivencia (individual y de la especie) y por lo tanto con-

30 Ficino podría haber optado, sin embargo, por reemplazar la voluptas por otro término con una tradición menos ligada a los placeres sensuales, como gaudium o la más neutra delectatio. Esta última es la palabra más usada por Tomás de Aquino en las quaestiones que versan sobre el placer (cfr. Summa theologica I-II, qq. 31-34). Véase al respecto Miner (2009). Recordemos que Ficino tomó muchos párrafos del Aquinate en la elaboración de su Comentario al Filebo, compuesto en simultáneo con los Apologi ad voluptatem. Ficino reflexiona en su comentario acerca del significado de los distintos términos para referirse al placer, y concluye que aunque voluptas suele asociarse a los placeres de los sentidos más bajos (el tacto, el olfato y el gusto), también se utiliza a menudo en el ámbito filosófico para referirse a la totalidad de las formas posibles del goce, incluyendo las de carácter intelectual. Ver Comentario al Filebo I, VII. 
siderarse placeres a posteriori. Los apólogos no dicen nada específico al respecto ${ }^{31}$. Sólo quedarían eliminadas todas aquellas actividades y objetos cuya única razón de ser es el placer inmediato que provocan. En este sentido, la posición de Ficino no puede asimilarse a la de antihedonismo radical. De haber deseado sostener esta posición, la voluptas jamás podría ser una carnada del Bien, y su función se limitaría a la de distorsionar la imagen auténtica de la bonitas celestial. En el reconocimiento de que el placer ocupa un lugar clave en la Creación podemos encontrar una apertura hacia la experiencia mundana, un rasgo frecuente en muchos textos del Quattrocento.

\section{Referencias}

Allen, D. C. (1944), The Rehabilitation of Epicurus and His Theory of Pleasure in the Early Renaissance, Studies in Philology, 41, 1-15.

Allen, M. J. B. (1989), «Phantastic Art, Magic, and the Idola» en M. Ficino, Icastes: Marsilio Ficino's interpretation of Plato's Sophist : five studies and a critical edition with translation (pp. 168-204), Berkeley, University of California Press.

Allen, M. J. B. (2000), «Introduction», en M. Ficino, The Philebus Commentary (pp. 1-58), Tempe: Arizona Center for Medieval Studies.

Allen, M. J. B. (1989), Icastes: Marsilio Ficino's interpretation of Plato's Sophist : five studies and a critical edition with translation, Berkeley, University of California Press.

Bokdam, S. (2010), «Le songe-érotique, vrai ou faux plaisir: du commentaire ficinien du Philèbe aux Sonnets pour Hélène», en M. T. Jones-Davies, M. Jones-Davies, \& F. Malhomme (Eds.), Le plaisir au temps de la Renaissance (pp. 19-38), Turnhout, Brepols.

Bossi, B. (2008), Saber gozar: estudios sobre el placer en Platón: Protágoras, Gorgias, Fedón, República, Filebo, Madrid, Trotta.

Boulègue, L. (2007), «Voluptas et beatitudo chez Marsile Ficin et Agostino Nifo. Théories du plaisir et détours du discours», en L. Boulègue \& C. Lévy (Eds.), Hédonismes: Penser et dire le plaisir dans l'Antiquité et à la Renaissance (pp. 233-253), París, Presses Universitaires Septentrion.

Brown, A. (2010), The return of Lucretius to Renaissance Florence, Cambridge, Harvard University Press.

Ficino, M. (2000), The Philebus Commentary, (M. Allen, Ed.), Tempe, Arizona Center for Medieval and Renaissance Studies.

Ficino, M. (2001), Platonic Theology. (J. Hankins \& Bowen, William, Eds., M. J. B. Allen \& J. Warden, Trads.) (Vols. 1-6), Cambridge, Harvard University Press.

Greenblatt, S. (2011), The Swerve: How the World Became Modern, Nueva York, W.W. Norton \& Cía.

Hankins, J. (1990), Plato in the Italian Renaissance, Leiden, Brill.

Kristeller, P. O. (1953), Il pensiero filosofico di Marsilio Ficino, Florencia, G.C. Sansoni.

Lefebvre, R. (2011), Platón, filósofo del placer, (M. Divenosa, Trad.), Buenos Aires, Biblos. Marcel, R. (2007), Marsile Ficin (1433-1499), París, Les Belles Lettres.

31 Platón tampoco se decide a ubicar los placeres «impuros» (que abarcan los sentidos, incluso si están relacionados con la supervivencia) en la jerarquía con la que termina el Filebo. Véase al respecto Bossi (2008). 
Marsh, D. (2003), Aesop and the humanist apologue, Renaissance Studies, 17(1), 9-26.

Miner, R. (2009), Thomas Aquinas on the Passions: A Study of Summa Theologiae, la2ae 22-48, Cambridge, Cambridge University Press.

Platón (1518), Platonis opera a Marsilio Ficino traducta: adiectis ad eius vitae \& operum enarrationem Axiocho ab Rodolpho Agricola: \& Aleyone ab Augustino Datho tralatis. (R. Agricola, A. Datus, J. Petit, \& J. B. Ascensius, Eds., M. Ficinus, Trad.), Vaenundantur ab Joanne Parvo \& Jodoco Badio.

Platón (2004), Fedón. Fedro, (L. Gil Fernández, Trad.), Madrid, Alianza. 
